\title{
Pluralidade cultural: Os esportes radicais na Educação Física escolar
}

\author{
Igor Armbrust" \\ Sheila Aparecida Pereira dos Santos Silva**
}

\begin{abstract}
Resumo: O currículo da Educação Física vem se renovando e observa-se que seus conteúdos tradicionais começam a compartilhar o espaço da escola com conteúdos atualmente bastante divulgados. Os Esportes Radicais encontram-se nessa situação, vêm atraindo o interesse de crianças em idade escolar e mostrando seu potencial educativo convergente com os objetivos da Educação Física. Em contrapartida, são identificadas resistências da parte dos educadores, que se expressam por meio de preocupações relativas à imagem de risco e imprevisibilidade envolvidos nesses conteúdos. Diante dessa situação, este ensaio tem como objetivo apresentar uma reflexão sobre a inserção dos Esportes Radicais nas propostas pedagógicas escolares.

Palavras-chave: Esportes Radicais. Complexidade. Educação. Física Escolar
\end{abstract}

\section{INTRODUÇÃO}

Com o crescimento das áreas de intervenção do profissional de Educação Física (EF) e dos interesses em atividades culturais e desportivas diversificadas que vem sendo amplamente divulgados pela mídia, surge a necessidade de aprofundar estudos sobre tais conteúdos emergentes. Os Esportes Radicais (ER) constam no rol destes conteúdos. Alguns estudos analisam tais atividades com vistas a verificar a pertinência e a possibilidade de serem inseridos na área educacional, expressando, no entanto, certas restrições às pesquisas

\footnotetext{
"Professor do curso superior em Educação Física da Universidade Camilo Castelo Branco, FEFISA e do curso de pós-graduação lato-sensu em Esportes e Atividades de Aventura da FMU. E-mail (correspondência): arm.igor@ig.com.br

"Professora dos cursos de mestrado e doutorado em Educação Física da Universidade São Judas Tadeu. Professora do curso superior em Educação Física - USJT. E-mail: sheila.silva@uol.com.br
} 
e elucidações existentes sobre o tema (UVINHA, 2004, CARDOSO; SILVA; FELIPE, 2006, MARINHO; SCHWARTZ, 2008).

Diante do estudo e da pesquisa sobre o assunto, e da experiência em trabalhar no contexto educacional com essa temática, identificamos certo viés na literatura, pois as publicações criam nomenclaturas alternativas com a finalidade de abrandar a reação de medo e preocupação provocada nas pessoas pela imagem já criada a respeito dos ER e tentam transmitir a ideia de "risco seguro", termo bastante utilizado nas publicações sobre lazer.

Temos observado que as publicações nem sempre abrangem o universo de possibilidades dos ER. Via de regra, tratam de distinções entre as Atividades Físicas de Aventura na Natureza (AFAN), entendidas como situações recreativas e contemplativas em ambientes naturais, argumentando que as pessoas não necessitam de aptidão física específica para o início de sua prática e que essas modalidades possuem em seu cerne o enfrentamento do risco de forma metafórica. Em contrapartida, os ER possuem muita competitividade, o que aumenta a exposição do praticante ao risco, contribuindo para a disseminação de práticas exaustivas e com pequeno número de praticantes (MARINHO; BRHUNS, 2006).

Tahara e Carnicelli Filho (2009), por sua vez, apontam que as AFAN, da forma como são propostas pelos espanhóis Betrán e Betrán (2006), conseguem abranger qualquer prática que desperte o instinto aventureiro e que tenha uma ligação profunda com o meio natural, representando uma atividade de diversão realizada no tempo livre. Contudo, não abarcam as possibilidades competitivas e/ou educativas que podem ser desenvolvidas pelas AFAN. A visão desses autores não considera as atividades realizadas em área urbana, possivelmente por não considerá-las como realizadas na natureza, mas que, todavia, possuem similaridades em seus elementos constitutivos.

Podemos afirmar que os entendimentos existentes sobre as AFAN carecem de devida comprovação por meio de estudos fundamentados em evidências provenientes das diversas práticas que esse universo abrange. Tal diagnóstico da literatura e, por outro 
lado, a intenção de contribuir com a discussão pedagógica da evolução dos conteúdos ensinados na EF, nos instigaram a discutir o envolvimento dessas práticas no campo educacional e como podem contribuir para o desenvolvimento da autonomia do indivíduo em sua forma de pensar e agir.

Para interpretação desse fenômeno, reflexão sobre as aproximações e distanciamentos dos ER do currículo escolar, em especial para o entendimento dessas atividades como conteúdos da EF escolar, nos baseamos no pensamento complexo de Edgar Morin, que permite trazer à pauta aspectos antes negados pela visão científica clássica como a imprevisibilidade, o acaso e a criatividade que, segundo nosso entendimento, são elementos fundamentais para as novas construções em educação.

\section{ESPORTES RADICAIS - 'Novo ESPORTE'}

Os ER começam a chamar atenção da comunidade acadêmica a partir de diferentes olhares: nos estudos do Lazer, como expressão das AFAN; nos de Treinamento Esportivo, com as estruturações funcionais para competidores e amadores de corridas de aventura, escalada, surfe e outros e, mais recentemente, na área escolar, já que como recurso educacional em programas de educação experiencial acontece há bastante tempo (PEREIRA; ARMBRUST, 2010).

Atualmente os ER, que se aglutinam como atividades de risco associadas ao movimento humano, valorizaram-se socialmente e têm ganhado novos significados. O risco destacado nos ER é manifestação inerente à sua prática e pensamos que é interessante que as pessoas se confrontem com ele para, só assim, poderem assimilar os valores vivenciais que se extraem dessa experiência. Spink (2001, p. 1277) explica que a ideia de risco desejado refere-se às "subjetividades dos praticantes em contato com as atividades ou eventos que têm incertezas quanto aos resultados ou consequências". Vivenciar situações arriscadas promove uma percepção da competência pessoal diante do evento. Para Le Breton (2006), trata- 
se de abandonar, provisoriamente, o conforto e a segurança, de levar o corpo ao limite de seus recursos, de ir o mais longe possível e de jogar com a imprevisibilidade.

Esse 'novo esporte' contém características do esporte tradicional, como o jogar com os outros e a busca da vitória, porém, há outras razões para que os praticantes busquem os ER como a inventividade de uma manobra, o aproveitamento do momento exato para tentar algo inusitado, ou ainda, para mudar determinados códigos no jogo ou desafio em busca de um sentido mais individualizado e, ao mesmo tempo, coletivo para a prática (PEREIRA; ARMBRUST; RICARDO, 2008).

Percebemos que muitas práticas esportivas que se caracterizam pelas regras institucionalizadas e por atividades motoras que visam ao alcance de recordes, podem ser vistas de outra forma e influenciadas por outros sentidos humanos como as sensações que o movimento pode proporcionar; os sentimentos com os quais os praticantes devem se confrontar para experimentar a atividade e a intuição enquanto elemento essencial na tomada de decisão.

De acordo com Marinho (2008), os aventureiros valorizam a espontaneidade possível nas atividades de aventura na natureza, já que elas parecem despertar aspectos do comportamento humano, menos controlados, tais como: atitudes hedonistas, cooperativas, sensibilizadoras, deslocamentos, experimentações, dentre outras possibilidades.

Isso mostra que o contexto esportivo está em constante transformação, o que exige uma releitura das práticas tradicionalmente aceitas e análise da possibilidade do surgimento e aceitação de 'novas' práticas, ou práticas reinventadas pela sociedade, já que existem relatos que mencionam aventureiros pré-históricos que percorriam montanhas, escalavam paredes gigantescas, remavam em grandes rios e mergulhavam para caçar (ASHCROFT, 2001), realizando movimentos que se assemelham aos ER da atualidade, ainda que executados com outra intencionalidade. 


\section{OS ESPORTES RADICAS E A COMPLEXIDADE}

Quando pensamos nos inúmeros objetivos de desenvolvimento humano presentes na EF escolar, pensamos que os ER podem ser abordados para promover a consciência para o enfrentamento das incertezas, o que pode colaborar com o processo do desenvolvimento do pensamento, julgamento e comportamento autônomos do indivíduo, seja em sua vida pessoal, seja voltado a questões do seu coletivo mais próximo, como também àquelas relativas ao cuidado com o planeta.

A autonomia humana é complexa já que depende de condições culturais e sociais para que se desenvolva e se implemente. Está ligada ao aprendizado de uma linguagem, de uma cultura, dos seus diferentes componentes, pois esse conhecimento é que permite a alguém fazer escolhas. Ou seja, sem diversidade cultural fica bastante difícil falar de autonomia já que é a diversidade que cria as condições que exigem que o indivíduo faça escolhas e, assim, amplie o seu processo de individuação. Ainda que seres permeados pela cultura na qual se vive no momento e, portanto, heterônomos em certo grau, não podemos negar que cada um, por sua herança genética, por suas condições e histórico de vida, é um indivíduo diferente de qualquer outro indivíduo e possui necessidades próprias para se desenvolver e alcançar uma vida plena e feliz. Sendo assim, mostrar às crianças e jovens que frequentam as escolas inúmeras possibilidades para buscarem a auto-realização, alcançarem satisfação, conhecerem atividades que lhes permitam maior autoconhecimento, conhecimento de opções de lazer e de práticas saudáveis, são justificativas fortes e suficientes para que se diversifiquem os conteúdos veiculados pelos educadores. Falar dessas condições humanas é falar da complexidade humana.

Morin (2007) explica que o pensamento complexo se propõe a integrar em si tudo o que põe ordem, clareza, distinção, precisão no conhecimento. Sua finalidade é ligar os entendimentos e aspirar ao conhecimento multidimensional. O pensamento complexo baseia-se na premissa da incompletude dos saberes e da incerteza; é 
fundamental distinguir os saberes, mas não isolá-los entre si. Nessa linha de raciocínio, os ER distinguem-se dos conteúdos tradicionais da EF escolar, mostram diferentes perspectivas, mas não deveriam ser tratados de maneira isolada dos demais conteúdos da EF ou de outros componentes curriculares.

Admitindo-se que a complexidade da vida humana contempla possibilidades de acaso, incerteza, ordem e desordem, podemos dizer que tal complexidade implica em aceitar a ambiguidade. Por aceitar a ambiguidade, reconhece os fenômenos humanos como dotados de liberdade e de criatividade, aspectos cuja manifestação pode ser vista como impertinente ou inaceitável no contexto escolar caso se desconsidere o pensamento complexo.

As aulas de EF escolar numa sociedade democrática e vistas na perspectiva complexa se integram aos princípios escolares, às condutas consequentes a tais princípios, e conduzem ao desenvolvimento humano dentro de padrões morais aceitos pela sociedade. Essa integração, no entanto, não prescinde de um princípio que respeita a dinamicidade da sociedade e de seus valores e, por isso, atualiza seus conteúdos e suas práticas. Além de considerar os conteúdos tradicionalmente trabalhados pelas escolas e trazidos pelos professores, os conteúdos da EF escolar podem ser ampliados com a diversidade contemporânea dos alunos que são, simultaneamente, receptores, agentes e transmissores de cultura, e atender aos seus interesses mesmo quando isso envolve conteúdos culturais considerados como emergentes.

Daolio (2004) pontua que as interpretações de cultura podem ser plurais e públicas, as pessoas são agentes de transformação e transmitem cultura. A cultura é universal, pois todas as pessoas a produzem, mas é também local, uma vez que é a dinâmica específica de vida que significa o que o ser humano faz. A cultura ocorre na mediação entre as pessoas e por meio de padrões de significados que fazem sentido num contexto específico. As valorizações culturais e de interesse das crianças e jovens sobre os esportes 
contemporâneos tem levado os ER em larga consideração (BETRÁN; BETRÁN, 2006).

Segundo Morin (2002), é possível verificar que práticas que fogem do cotidiano de entendimento de atividades para um determinado grupo ou indivíduo podem estimular a atenção significativa para uma determinada situação imprevisível. Pensamos que essa afirmação nos remete à possibilidade de retratar nas aulas de $\mathrm{EF}$ diversos assuntos que contribuam para o desenvolvimento do ser humano nos aspectos biopsicosociocultural, entre eles, os ER.

Os ER ainda podem ser explorados na EF escolar para discutir relações grupais ou subculturas. Uvinha (2001) comenta o fenômeno das aproximações grupais para uma determinada prática, como é o caso do skate, quando tais aproximações se evidenciam nas linguagens utilizadas, nas vestimentas, nas condutas morais e éticas, na busca por manobras que expressem radicalidade, no sentido de extrapolar a lógica de entendimento, onde a surpresa e a intuição podem ser elementos ótimos para as criações de novas manobras e melhora das capacidades percepto-motoras. Assim, também, são os grupos de parkour que se reúnem em locais que se tornam significativos para os praticantes, locais que muitas pessoas adotariam como ambientes de contemplação ou de simples passagem, apresentando como resultado uma (re)significação do ambiente por ação desses grupos (CARVALHO; PEREIRA, 2008).

\section{OS ESPORTES RADICAIS NA ESCOLA: UMA REFLEXÃO SOBRE OS CONTEÚDOS ESCOLARES}

Os Parâmetros Curriculares Nacionais (PCN) destacam que a cultura corporal de movimento a ser ensinada na escola implica em práticas como os jogos, as lutas, as atividades rítmicas e danças, os esportes e as ginásticas como produções culturais visando ao ensino e à aprendizagem (BRASIL, 1998). Os conteúdos dessa cultura, se por um lado, cumprem o papel de transmitir uma tradição 
de práticas corporais construída historicamente na área e fazer com que os alunos se apropriem e se enriqueçam com ele, por outro lado, devem ser renovados para que sejam atuais e significativos aos alunos porque contextualizados em seu meio e munidos dos códigos e linguagens dos grupos nos quais foram gerados e vem sendo vividos.

Sabemos que essa dinâmica faz parte da natureza dos conteúdos escolares referentes às práticas corporais já que essas sofrem influência de movimentos novos, e que chegam à contemporaneidade depois de terem passado por um processo no qual foram modificadas ou reinventadas (ARMBRUST; LAURO, 2010).

Desta forma, quando se pensa em conteúdos, englobam-se suas dimensões conceituais, atitudinais e de procedimentos (COLL, 2000; DARIDO, 2005) e, pensando nisso, podemos afirmar que os ER como conteúdos escolares possuem essas mesmas dimensões não apresentando qualquer desvantagem em relação a outros conteúdos tradicionalmente ensinados na EF em especial, ou na escola, em geral.

Vejamos um exemplo: se pensarmos nas práticas de caminhada na natureza, é possível verificar que, além do contato com o meio, ocorre trabalho em equipe, a ajuda ao próximo para passar um determinado trecho, a espera do outro para não dissolver o grupo e para tomar cuidado com aquele que fica para trás ou tem um ritmo diferenciado. Pode-se, com orientações adequadas, processar informações da fauna e da flora, os cuidados com os ambientes, as condutas de mínimo impacto e toda essa discussão pode ser levada para o interior da escola, ou para o ambiente familiar o que costuma ocorrer com mais facilidade quando são adotados princípios curriculares transdisciplinares.

Tradicionalmente, costuma-se entender que essas atividades quando inseridas no currículo escolar, vinculam-se e são de responsabilidade da EF e que suas possibilidades pedagógicas se restringem à melhoria do condicionamento físico e das habilidades motoras dos alunos. No entanto, uma análise isenta de preconceitos 
a respeito dos ER permite visualizar que há uma enorme gama de competências que tais experiências podem desenvolver no sujeito que interage com o meio, que possibilitam identificar inúmeras maneiras de interagir e preservá-lo, que permitem refletir a respeito de como e quanto o meio influencia o indivíduo. Em suma, os ER podem ser vistos como temas geradores de abordagens transdisciplinares e, portanto, servirem como ferramenta para o coletivo de professores e de disciplinas que compõem o currículo.

Trata-se, portanto, de não apenas visualizar mudanças no planejamento da EF, mas de fomentar o trabalho coletivo dos educadores e interferir em diversos planos de ensino. Conforme comenta Morin (2002), os apontamentos interdisciplinares precisam seguir os entendimentos complexos de educar por meio de diferentes vias de acesso ao aluno e em diferentes cenários. Não adianta apenas levar os alunos para ambientes não-urbanos no qual se entende que é maior o contato com a natureza; a natureza deve ser contemplada, conversada, vivida nos ambientes intra e extra-escolar com vistas a estimular a consciência para as questões ambientais no cotidiano de todos.

No processo de conhecer e no desenvolvimento de atitudes autônomas e responsáveis, o indivíduo precisa aprender a enxergarse no mundo, enxergar as respostas que lhe são pedidas pelas mais diversas situações, e assumir as consequências, positivas ou não, de suas condutas. Ser cidadão do mundo, como afirma Morin (2007) implica em que as pessoas sejam capazes de identificar como e quanto elas influenciam o meio e são influenciadas por ele. Nessa linha de pensamento, a inclusão dos ER como possibilidade curricular cria a possibilidade de estimular o desenvolvimento do ser auto-ecoorganizador, que organiza a si mesmo com a ajuda do meio ambiente (MORIN, 2007).

Em decorrência disso, surge a questão: É possível esperar que a formação de atitudes e condutas ocorra de forma permanente se as propostas pedagógicas, seus objetivos e conteúdos não fizerem 
sentido para os alunos? Pensamos que não. As propostas pedagógicas precisam mostrar e fazer sentido para o aluno que, a partir delas, cultivará os saberes para sua vida, para a vida no seu meio e no seu tempo.

Nas grandes metrópoles pode parecer inatingível incluir os ER com o argumento da dificuldade em deslocar os alunos para grandes distâncias, já que 'parece' que a natureza está distante das cidades. No entanto, vemos outras possibilidades de responder a essa dificuldade afirmando que é possível um novo entendimento a respeito das estratégias de ensino utilizadas para que os alunos conheçam a natureza e se interessem por ela. Chamamos a atenção para o fato dos ER poderem ser explorados na área urbana, sem deslocar os alunos para meios distantes daqueles em que vivem e, dessa forma, promover, eficazmente, o desenvolvimento de seus saberes ambientais (PEREIRA; ARMBRUST, 2010).

Nessa perspectiva, seria preciso que os educadores e as escolas repensassem o conceito tradicional de natureza, ou melhor, que fossem à raiz desse conceito que pode ser entendido como aquilo que nasce, da forma que nasce (HEIDEGGER, 1949). Quando o pensamento complexo coloca a necessidade da reaproximação do ser humano ao ambiente natural, entendemos que o ambiente natural para quem nasceu numa cidade é a área urbana, ainda que não neguemos o quanto é agradável e importante ter momentos em que se sai da cidade para outros lugares como as praias, o campo, as montanhas.

Visualizamos os ER como um excelente norteador da renovação dos conteúdos e das práticas escolares, lembrando que tais conteúdos específicos, como outros quaisquer, não deveriam ser selecionados por se pensar que possuem fins em si mesmos, mas seriam inclusos no currículo escolar aqueles que passassem pelo crivo da abrangência da sua potencialidade no sentido de promover o desenvolvimento das pessoas, propiciando apropriação e produção de conhecimentos, valores e atitudes. 
Marinho (2008) ao estudar praticantes de atividades de aventura observou que estas pessoas podem ter uma estreita relação com a superação de obstáculos, não apenas físicos, mas também simbólicos e imaginários, não necessariamente os mais arriscados e difíceis, mas que, de alguma forma, agregam o sentido de novidade, do desconhecido e do não-explorado. Corroborando com essa ideia, Pereira e Armbrust (2010) afirmam que esses conhecimentos, valores e atitudes são potencializados quando há uma intencionalidade de alguém, no caso, um professor, colocando situações que desafiem o grupo de alunos.

Já é de longa data que os sistemas educativos tradicionais vêm sofrendo críticas por privilegiar a abordagem fragmentada de conteúdos se descuidando de promover a ligaça?o entre os diferentes componentes curriculares. A organizaça?o do conhecimento sob a forma de disciplinas é vista como u?til quando se toma como pressuposto que o conhecimento é fragmentado, fechado em si mesmo, e deve ser aprendido por meio de experiências parceladas.

Por concordarmos com Morin (2002) que o ser humano é uno e indivisível, discordamos dessa tradição e nos animamos pelo princi?pio do pensamento que nos estimula a integrar os conteúdos que nos parecem separados com vistas à busca de sua melhor significatividade para os educandos, bem como sua melhor efetividade em relação aos objetivos educativos a que a escola se propõe.

\section{ESPORTES RADICAIS: O SÓLIDO SE DESMANCHA NO AR}

Quando pensamos em nós mesmos e nos seres do mundo, de uma maneira geral, temos a impressão de que tudo é sólido. Aprendemos isso na escola: corpos são entes sólidos que ocupam lugar no espaço.

Essa verdade que parece inquestionável e mais do que evidente, já que a constatamos a todo momento, hoje já é lida de outra maneira. 
Tudo depende da forma como vemos e dos instrumentos que temos à nossa disposição para ver.

Quanto mais os instrumentos permitem avançar rumo ao conhecimento das menores partículas existentes no mundo e da organização estrutural dos seres vivos, mais nos deparamos com a chocante constatação de que não somos os corpos sólidos que imaginamos. Entre cada infinitesimal micro partícula que nos compõe existem espaços o que nos convida a encarar que, na verdade, somos um amontoado de partículas que se deslocam pelo espaço, unidas por algum tipo de energia. Ou seja, a nossa noção de sólido se desmanchou pelo ar.

No entanto, ao invés dessa maneira de nos encararmos sugerir qualquer valorização ou desvalorização do que seja o ser humano, simplesmente nos desafia a mudarmos o nosso modo de ver e compreender a realidade.

E por que, então, não mudarmos a nossa forma de encararmos o que é a educação escolar e o que são os conteúdos que são utilizados para desenvolver seres humanos?

Quando olhamos para nós mesmos na busca daquilo que temos de sólido, estável, confiável, seguro, percebemos que tais ideias são ilusões e que, na verdade, o que mantém a nossa ordem e a nossa organização estrutural é o que entendemos pelo conceito de energia. Em outras palavras, se existe algo invariante na vida sobre a face da terra, esse invariante é a energia.

O próprio conceito de energia é bastante amplo e pode ser visto pelo olhar da Física que define energia como a capacidade que possui um sistema de realizar um trabalho, ou ainda da termodinâmica cuja lei da conservação estabelece que ela pode ser transformada, ainda que não seja possível criá-la ou destruí-la. A conservação da energia no universo já é algo admitido desde a Antiguidade, quando o matemático grego Pitágoras afirmou que tudo muda, mas que nada é perdido. Neste entendimento, tudo o que existe no mundo, do mais simples ao mais complexo, das estruturas microscópicas aos sistemas sociais mais amplos, possui energia: as plantas, os animais, 
os próprios seres humanos, os sistemas, as máquinas, as pedras, os edifícios, os monumentos, os contornos, as formas e movimentos de tudo que existe representam concentrações e transformações de energia.

Tentando fazer uma analogia com a discussão sobre conteúdos escolares que desenvolvemos até este ponto, nos questionamos: Onde se situa e como encontrar a energia que agrega as experiências escolares, que organiza a estrutura do currículo e que sustenta a vida dos seres que frequentam os ambientes escolares?

A resposta não é única e, diante disso, pensamos que seria melhor pensar em um critério para selecionar conteúdos e, esse critério, seria a energia presente em cada um deles. E como detectar tal energia? Provavelmente fazendo aos conteúdos uma série de perguntas: Tal conteúdo consegue chamar para si diferentes olhares e ser passível de diferentes formas de estudá-lo e de ser assimilado pelos aprendizes? A energia emanada de tal conteúdo consegue estabelecer contato com a energia presente na curiosidade dos alunos. Tal conteúdo tem energia para despertar no aluno a vontade de empreender esforços para se aproximar dele em busca de satisfazer algum tipo de desconforto, seja físico, emocional, cognitivo ou social? Tal conteúdo estimula os educadores a trabalharem em equipe permitindo que cada um traga sua forma própria de estudá-lo e de ensiná-lo? A energia presente nesse conteúdo é uma energia que agrega ou que desagrega as pessoas, sejam elas professores ou alunos?

De acordo com esse crivo, os ER parecem ser dotados de uma grande magnitude de energia agregadora, comunicativa e desencadeadora do desejo de realização.

Da mesma forma que um arquipélago é composto por diversas ilhas e que, para conhecê-lo, é preciso visitá-las, os ER podem ser vistos como uma das ilhas componentes do arquipélago, desde que revisemos o nosso conceito de ilha. Ilha sendo encarada como unida a outras ilhas ou aos continentes por meio da água que a circunda, e não isolada pela água como se costuma pensar. Nessa metáfora, os 
ER podem se unir aos demais conteúdos tradicionalmente abordados pela EF escolar, como também ser a água que permeia e une outros componentes curriculares.

Em outras palavras, incluir o estudo dos ER como conteúdo escolar não tem em vista suprir ou suprimir outros conteúdos abordados, mas como um saber a mais e que possui suas qualidades para melhor enriquecimento do acervo cultural dos alunos (PEREIRA; ARMBRUST, 2010), uma nova energia a animar a vida na escola.

Constatando, ainda, certa dificuldade para os ER serem empregados na EF escolar, estimulamos os educadores a refletirem sobre os seguintes aspectos. O diferencial dos ER se encontra, primeiramente, no enfrentamento do risco. Envolvem atividades nas quais os indivíduos se colocam em reais situações de risco e que precisam saber o que fazer para sair delas. Isso implica em aprendizado para o gerenciamento e para uma convivência consciente e assumida a respeito desse enfrentamento. De certo modo, tais experiências modificam a relação da pessoa com as sensações e com o sentimento do medo em diferentes situações cotidianas, vividas individualmente ou nas relações sociais. Aprender a lidar com o medo diminui o isolamento e a fuga do ser humano que se abriga sob atitudes cautelosas e protecionismos em demasia. Pensamos que os riscos estão presentes a todo o momento na vida humana e que é inevitável camuflá-los na tentativa de se proteger.

Tahara e Carnicelli Filho (2009) afirmam que o risco é inerente ao homem e está presente em qualquer setor da vida humana. Isso também se aplica à prática esportiva, mesmo que realizada com o objetivo de diversão, havendo situações em que ocorre um cálculo minucioso do perigo. Ainda que haja este cálculo e sejam tomados os devidos cuidados na prática dos ER, o risco sempre existe e talvez seja esse o fator que desencadeia maior prazer no praticante.

Outro ponto a considerar em relação aos ER é que tipo de atitude em relação à competição e à vitória que ele permite aprender. 
$\mathrm{Na}$ maioria das práticas de ER, a identificação clara de perdedores e ganhadores tão presente nos esportes coletivos, é dissolvida. Nos ER, a vitória ou derrota está intrinsecamente ligada ao indivíduo que desafia suas habilidades e se coloca em confronto consigo mesmo.

Tomemos como exemplo uma escalada. Imagine que em determinado ponto da via, a pessoa não consegue seguir em frente, suas mãos não suportam o seu corpo, os lugares nos quais se agarram são pequenos e ela se encontra a uma certa altura que já lhe causa certa apreensão e desconforto. A decisão do enfrentamento da dificuldade é intrínseca e pode acontecer do indivíduo se dar por derrotado naquele movimento. Essa "derrota", no entanto, ao invés de eliminar-lhe o desejo pelo desafio e pela superação pode, na verdade, estimulá-lo a voltar numa outra ocasião para tentar novamente. Mesmo que sua decisão tenha sido a de retroceder por ter esgotado suas possibilidades e vontade de enfrentar essa via, isso não o impede de ter novamente o desejo de enfrentar a mesma dificuldade.

Pensando nessa situação, fica difícil afirmar se o indivíduo foi derrotado ou não, já que seu recuo pode ter sido momentâneo, muitas vezes em busca de melhores condições para enfrentar o desafio em outra ocasião. Nesse exemplo fica claro que o indivíduo se coloca à prova diante de condições para as quais, inicialmente, se sente preparado, mas que, diante de uma dificuldade que julga insuperável no momento, retrocede e se prepara melhor para empreender uma nova tentativa. Pode-se, então, definir se o praticante se sagrou perdedor ou vencedor? O que significa vencer numa situação como essa? O mais importante, portanto, é a oportunidade de cada indivíduo viver aquele momento, fazer sua auto-análise e extrair lições próprias e significativas dessas experiências.

Entre tantas lições possíveis, se situam o aprender a ser responsável por si mesmo, a ser responsável pelos outros e pela natureza, entendida como o lugar de convívio. 
Os ER, mesmo aqueles entendidos como individuais, geralmente são praticados em companhia de alguém. Podemos ver pessoas sozinhas em cima de um skate, mas, dificilmente se encontra desacompanhado de outros skatistas. Os ER costumam promover um convívio interpessoal visto como fundamental já que aumenta a motivação do grupo e confere a agradável sensação de pertencer a algo que tem significados compartilhados.

É bastante interessante observar que, comumente, existe a preocupação dos mais experientes com aqueles que estão tentando aprender certo movimento ou manobra e essa solidariedade vai além, podendo-se observar que sempre existe alguém para emprestar um skate quando uma pessoa se aproxima do grupo com o desejo de praticar, mas que não possui o equipamento.

Os ER promovem o desenvolvimento de verdadeiras comunidades que, além de se ocuparem do auxílio entre seus membros, também se ocupam em conseguir recursos e trabalham recuperando espaços urbanos ou outros espaços de prática quando, por exemplo, uma parte da pista de skate se quebra.

Diante de tantas situações com as quais já nos deparamos e que envolvem os ER, constatando a expansão de suas modalidades, do número de praticantes e dos locais que passaram a aceitar sua prática, nos perguntamos pelas razões que ainda os impedem de compor o universo escolar.

Se pensarmos que a escola pode ser um lugar estimulador de saberes culturais diferenciados utilizados para a formação de um cidadão crítico das atuais condições em que vive e que seja ativo no cuidado com o planeta, entendemos essas práticas emergentes como passíveis de serem contempladas no âmbito escolar.

Se visualizarmos o currículo escolar como uma entidade complexa, e se entendermos que complexo significa tecido, trama de componentes que atuam em conjunto, pensamos que os ER podem ser significativos para promover a riqueza da convivência humana, constituir uma via para expansão de saberes. 
Podemos, então, pensar nas possibilidades de integrar os ER ao currículo escolar como uma das ferramentas de promoção da causa do bem estar do ser humano num planeta sustentável? 
Cultural Plurality: The Radical Sports In Physical Education at School

Abstract: The Physical Education curriculum has been renewed and we can notice that its traditional contents, starting to share time at school with current contents published. The radical sports in this situation are attracting interest of children and teenagers in school age, showing the educational potential convergent with the physical education purpose. In contrast, some resistances are identified by the educators, who expressed themselves through concerns related risk images and unpredictability envolved in the experience of these contents. Faced in this situation, based on the complex thought grounded in Edgar Morin, the objective of this test is present a reflection about Radical Sports insertion in the pedagogical proposals. Keywords: Radical Sports. Complexity. Physical Education

\section{El Pluralismo cultural: Desportes Radical en la Educación Física Escolar}

Resumen: El plan de estudios de Educación Física ha sido renovado y se observa que su contenido tradicional, comienzan a compartir espacio en la escuela, devido a su actual divulgación de nuevos contenidos. Los Deportes Radicales se encuentran en esta situación, han atraído la atención de niños que frecuentan la escuela y han mostrado su potencial educativo de convergencia con los objetivos de la Educación Física. Por el contrario, resistencias se identifican por parte de los educadores, que expresan su preocupación com base en el image de riesgo e imprevisibilidad relacionados a estos contenidos. Ante esta situación, con el apoyo en el pensamiento complejo basado en Edgar Morin, el presente ensayo tiene como objetivo presentar una reflexión sobre la inclusión de los deportes radicales en las propuestas pedagógicas. Palabras-clave: Deporte Radical. Complejidad. Educación Física Escolar 


\section{REFERÊNCIAS}

ARMBRUST, I.; LAURO, F. A. A. Skate e suas possibilidades educacionais: proposta metodologia. Motriz, Rio Claro, v. 16 n. 3, p. 799-807, jul./set. 2010. Disponível em: <http://cecemca.rc.unesp.br>. Acesso em: out. 2010.

ASHCROFT. F, A vida no limite: a ciência da sobrevivência. Rio de Janeiro: Zahar, 2001.

BETRÁN, J. O.; BETRÁN, A. O. Proposta pedagógica para as Atividades Físicas de Aventura na Natureza (AFAN) na EF do ensino médio. In: MARINHO, A.; BRHUNS, H. T. (Org.). Viagens, lazer e esporte: o espaço da natureza. Barueri, SP: Manole, 2006. p. 180-210.

BRASIL. Secretaria de Educação Fundamental. Parâmetros curriculares nacionais. Brasília: MEC/SEF, 1998.

CARDOSO, A. R.; SILVA, A.; FELIPE, G. R. A educação pela aventura: desmistificando sensações e emoções. Motriz, Rio Claro, v. 12 n. 1 p. 77-87, jan./abr. 2006.

CARVALHO, R. G.; PEREIRA, A. P. Percursos alternativos: o Parkour enquanto fenômeno (sub)cultural. Revista Portuguesa Ciência Desporto, Lisboa, v. 8, n. 3, p. 427-440, 2008.

COLL, C. S. Os conteúdos na EFE. In: COLL, C. et al. Os conteúdos na reforma: ensino aprendizagem de conceitos, procedimentos e atitudes. Porto Alegre: Artmed, 2000. p. 9-16.

DAOLIO, J. Educação Física e o conceito de cultura. Campinas, SP: Autores Associados, 2004.

DARIDO, S. C. Os conteúdos da EF na escola. In:DARIDO, S.C; RANGEL, I. C. A. EF no ensino superior: EF na Escola. Implicações para a prática pedagógica. Rio de Janeiro: Guanabara Koogan, 2005. cap.5, p. 64-79.

HEIDEGGER, M. A essência do fundamento. 3. ed. Lisboa, Portugal: Edições 70, 1949.

LE BRETON, D. Risco e lazer na natureza. In: MARINHO, A.; BRUHNS, H. T. (Org.). Viagens, lazer e esporte: o espaço da natureza. Barueri, São Paulo: Manole, 2006. p. 94-117.

MARINHO, A. Lazer, aventura e risco: reflexões sobre atividades realizadas na natureza. Movimento, Porto Alegre, v. 14, n. 2, p. 181-206, maio/ago. 2008. Disponível em: <http://seer.ufrgs.br/Movimento/article/view/5756/3364>. Acesso em: nov. 2011

MARINHO, A.; BRHUNS, H. T. (Org.). Viagens, lazer e esporte: o espaço da natureza. Barueri, SP: Manole, 2006. 
MARINHO, A.; SCHWARTZ, G. M. Atividades de aventura como conteúdo da Educação Física: reflexões sobre seu valor educativo. Revista Digital, Buenos Aires, v. 10, n. 88, set. 2008. Disponível em: <http://www.efdeportes.com> Acesso em: maio 2009.

MORIN, E. Introdução ao pensamento complexo. 3. ed. Porto Alegre: Sulina, 2007.

Os sete saberes necessários à educação do futuro. 6. ed. São Paulo: Cortez; 2002.

PEREIRA, D. W.; ARMBRUST, I. Pedagogia da aventura. Jundiaí, SP: Fontoura, 2010.

PEREIRA, D. W.; ARMBRUST, I.; RICARDO, D. P. Esportes radicais, de aventura e ação: conceitos, classificações e características. Revista Corpoconsciência, São Paulo, v. 12, n. 1, p. 35-56, jan./jun. 2008.

SPINK, M. J. P. Tópicos do discurso sobre risco: risco-aventura como metáfora na modernidade tardia. Caderno Saúde Pública, Rio de Janeiro, v. 17, n. 6, p. 12771288, nov./dez. 2001. Disponível em: <http://www.scielo.br/scielo.br>. Acesso em: mar. 2004.

TAHARA, A. K.; CANICELLI FILHO, S. Atividades físicas de aventura na natureza (AFAN) e academias de ginástica: motivos de aderência e benefícios advindos da prática. Movimento, Porto Alegre, v. 15, n. 3, p. 187-208, jul./set. 2009. Disponível em: <http://seer.ufrgs.br/Movimento/article/view/4917/5586> Acesso em: nov. 2011.

UVINHA, R. R. Esportes radicais nas aulas de Educação Física no ensino fundamental. In: MOREIRA, E. C. (Org.) Educação Física Escolar: desafios e propostas. Jundiaí: Fontoura, 2004. p. 99-111.

UVINHA, R. R. Juventude, Lazer e Esportes Radicais. São Paulo. Manole, 2001.

Recebido em: 26/08/2011

Aprovado em: 05/03/2012 
